\title{
Gastric emptying is accelerated in diabetic BB rats and is slowed by subcutaneous injections of amylin
}

\author{
A. A. Young, B. Gedulin, W. Vine, A. Percy, T.J. Rink \\ Amylin Pharmaceuticals Inc., San Diego, California, USA
}

\begin{abstract}
Summary Gastric emptying was measured in normal and insulin-treated spontaneously diabetic BB rats using the retention of an acaloric methylcellulose gel containing phenol red delivered by gavage. Dye content in stomachs removed after killing 20 min later was determined spectroscopically, and was compared to that in rats killed immediately after gavage to assess emptying. Diabetic rats had a markedly greater gastric emptying ( $90.3 \pm 1.7 \%$ passed) compared to normal Harlan Sprague Dawley rats (49.1 $\pm 4.7 \%$ passed; $p<0.001)$ and non-diabetic BB rats $(61.1 \pm 9.2 \%$ passed; $p<0.001)$. The pancreatic beta-cell peptide, amylin, which is deficient in insulin-dependent diabetes mellitus, dose-dependently inhibited gastric emptying in both normal and diabet-
\end{abstract}

ic rats. The $\mathrm{ED}_{50}$ of the response in normal rats measured by phenol red and novel $\left[3-{ }^{3} \mathrm{H}\right]$ glucose gavage techniques was approximately $0.4 \mu \mathrm{g}$. This dose was estimated to increase plasma amylin concentration by a mean of approximately $20 \mathrm{pmol} / 1$ to concentrations within the range observed in vivo. It is proposed that amylin could participate in the physiological control of nutrient entry into the duodenum, and that the accelerated gastric emptying seen in BB rats could be related to their lack of amylin secretion. [Diabetologia (1995) 38: 642-648]

Key words $\mathrm{BB}$ rat, gastric emptying, amylin, incretins, $\left[3-{ }^{3} \mathrm{H}\right]$ glucose islet amyloid polypeptide.
Disturbances of gastric emptying are a common feature of diabetes mellitus. However, with incomplete information about the natural history of disordered gastric motor function in diabetes, the literature on gastric emptying in diabetes is acknowledged to be confusing [1]. Many reports do not distinguish between juvenile-onset insulin-dependent (IDDM) and maturity-onset non-insulin-dependent (NIDDM) forms of diabetes. Further, as it is often difficult to do so, many reports do not distinguish between gas-

Received: 29 August 1994 and in revised form: 6 December 1994

Corresponding author: Dr. A. A. Young, Amylin Pharmaceuticals Inc., 9373 Towne Centre Drive, San Diego, CA 92121, USA Abbreviations: BB, Biobreeding; HSD, Harlan Sprague Dawley; IDDM, insulin-dependent diabetes mellitus; NIDDM, non-insulin-dependent diabetes mellitus, GIP, gastric inhibitory polypeptide; $\mathrm{ED}_{50}$, median effective dose. tric dysfunction secondary to autonomic neuropathy and that independent of it. Gastroparesis and delayed gastric emptying appear to be common features associated with autonomic neuropathy [2]. On the other hand, in diabetic subjects with no evidence of autonomic dysfunction, it has been reported that gastric emptying may actually be accelerated $[3,4]$. Since digestion of carbohydrate and absorption of glucose occurs very rapidly and efficiently once food passes from stomach to intestine, the rate of gastric emptying is an important factor in the appearance of glucose after a meal.

While some authors have considered that overrapid glucose absorption may underlie the postprandial hyperglycaemia seen in some IDDM subjects [5], and have speculated that accelerated gastric emptying might underlie this over-rapid absorption, few studies have addressed this possibility. Using an established phenol red dye technique [6], we set out to examine gastric emptying in a rodent model of spon- 
taneous autoimmune diabetes, the insulin-treated BB rat. We found that gastric emptying was accelerated in such rats, in line with a similar result published while the present paper was in preparation [7].

The mechanisms that could lead to accelerated gastric emptying in IDDM are not clear. Such an effect would not have been predicted from the observations $[8,9]$ that hyperglycaemia per se tends to slow gastric emptying, and that high (rather than low) insulin concentrations can accelerate emptying [10].

The 37 amino acid peptide, amylin (sometimes referred to as islet amyloid polypeptide), which is normally cosecreted from the pancreatic beta cells with insulin in response to glucose and other nutrient stimuli [11], as well as in response to gut-derived incretins [12], is deficient in IDDM [13]. Amylin is reported to potently limit the postprandial increase in plasma glucose $[14,15]$. Using both an established phenol red method, and a novel tritiated glucose gavage technique, we investigated whether amylin might achieve this action by slowing gastric emptying.

On examining the effects of subcutaneous injections of rat amylin on gastric emptying in normal and diabetic rats, we found that amylin dose-dependently inhibited gastric emptying in both normal and diabetic rats, and did so with doses that produced changes in plasma amylin concentration that were confined to the range reported in vivo. A preliminary report of this work has been published in $a b-$ stract form [16].

\section{Materials and methods}

Animals. Male Harlan Sprague Dawley (HSD) rats (161$244 \mathrm{~g}$ ) and Biobreeding (BB) rats (181-405 g) obtained from an in-house colony originally derived from Møllegård Breeding Center, Denmark in 1989 were used. When BB rats were confirmed as being diabetic by presence of glycosuria on at least 2 days, they were treated with daily s. c. injections of ultralente recombinant human insulin (Humulin-U, Eli Lilly, Indianapolis, Ind., USA). Insulin therapy was aimed at maintaining glucose but minimizing ketones in the urine, in order to avoid hypoglycaemic deaths. In fact, glycosuria was present in $88 \%$ of measurements and ketonuria in $52 \%$. The average duration of diabetes was $53 \pm 5$ days, and daily insulin requirements were $4.7 \pm 0.3$ units. All animals were housed at $22.7 \pm$ $0.8^{\circ} \mathrm{C}$ in a $12: 12 \mathrm{~h} \mathrm{light} \mathrm{:} \mathrm{dark} \mathrm{cycle} \mathrm{(experiments} \mathrm{being} \mathrm{per-}$ formed during the light cycle) and were fed and watered ad libitum (Diet LM-485, Teklad, Madison, Wis., USA).

The determination of gastric emptying by the method described below has usually been performed after a fast of approximately $20 \mathrm{~h}$ to ensure that the stomach contained no chyme that would interfere with spectrophotometric absorbance measurements. However, diabetic rats treated with Ultralente insulin could not be fasted for $20 \mathrm{~h}$. Periods of fasting of longer than $6 \mathrm{~h}$ resulted in hypoglycaemia. Such animals were therefore fasted for only $6 \mathrm{~h}$ before measurement of gastric emptying. Non-diabetic rats were deprived of food for either 6 or $20 \mathrm{~h}$ prior to the study. We have noted that even non-diabetic BB rats have elevated glycated haemoglobin concentrations, possibly indicating subclinical insulitis.
Both non-diabetic HSD rats and non-diabetic BB rats animals were therefore used in comparisons with diabetic rats. Thus, there were five treatment groups:

(1) Non-diabetic HSD rats, fasted $6 \mathrm{~h}, n=8$, age $=69 \pm 1$ day, weight $=239 \pm 5 \mathrm{~g}$.

(2) Non-diabetic BB rats, fasted $6 \mathrm{~h}, n=6$, age $=271 \pm 34$ days, weight $=352 \pm 36 \mathrm{~g}$.

(3) Diabetic BB rats, fasted $6 \mathrm{~h}, n=10$, age $=144 \pm 10$ days, weight $=255 \pm 9 \mathrm{~g}$.

(4) Non-diabetic HSD rats, fasted $20 \mathrm{~h}, n=20$, age $=62 \pm 1$ day, weight $=201 \pm 10 \mathrm{~g}$.

(5) Non-diabetic BB rats, fasted $20 \mathrm{~h}, n=7$, age $=158 \pm 9$ days, weight $=283 \pm 30 \mathrm{~g}$.

Measurement of gastric emptying - phenol red method. Gastric emptying was measured using a modification [6] of the original method of Scarpignato et al. [17]. Briefly, conscious rats received by gavage, $1.5 \mathrm{ml}$ of an acaloric gel containing $1.5 \% \mathrm{me}$ thyl cellulose (M-0262, Sigma Chemical Co, St Louis, Mo., USA) and $0.05 \%$ phenol red indicator. Twenty minutes after gavage, rats were anaesthetized using $5 \%$ halothane, the stomach exposed and clamped at the pyloric and lower oesophageal sphincters using artery forceps, removed and opened into an alkaline solution which was made up to a fixed volume. Stomach content was derived from the intensity of the phenol red in the alkaline solution, measured by absorbance at a wavelenght of $560 \mathrm{~nm}$. In most experiments, the stomach was clear. In other experiments, particulate gastric contents were centrifuged to clear the solution for absorbance measurements. Where the diluted gastric contents remained turbid, the spectroscopic absorbance due to phenol red was derived as the difference between that present in alkaline vs acidified diluent. In separate experiments on seven rats, the stomach and small intestine were both excised and opened into an alkaline solution. The quantity of phenol red that could be recovered from the upper gastrointestinal tract within $20 \mathrm{~min}$ of gavage was $89 \pm 4 \%$; dye which appeared to bind irrecoverably to the gut luminal surface may have accounted for the balance. To compensate for this small loss, the percentage of stomach content remaining after $20 \mathrm{~min}$ was expressed as a fraction of the gastric content recovered from control rats killed immediately after gavage in the same experiment. Percent gastric content remaining $=($ absorbance at $20 \mathrm{~min}) /($ absorbance at $0 \mathrm{~min}) \times 100$.

Treatment groups - phenol red method. In baseline studies (where amylin was not injected), gastric emptying over $20 \mathrm{~min}$ was determined in the five treatment groups described above. In dose-response studies, rat amylin (Bachem, Torrance, $\mathrm{Ca}$ lif., USA) dissolved in $0.15 \mathrm{~mol} / 1$ saline, was administered as a $1.0 \mathrm{ml}$ subcutaneous bolus in doses of $0,0.01,0.1,1,10$ or $100 \mu \mathrm{g} 5 \mathrm{~min}$ before gavage in $46 \mathrm{HSD}$ (non-diabetic) rats fasted $20 \mathrm{~h}(n=17,2,8,8,6,5$, respectively) and in 29 diabetic BB rats fasted $6 \mathrm{~h}$ dosed with $0,0.1,1.0,10$ or $100 \mu \mathrm{g} 5 \mathrm{~min}$ before gavage ( $n=10,3,3,3,10$ respectively).

Measurement of gastric emptying - tritiated glucose gavage. In a separate series of experiments, we explored the use of a technique that would (1) yield time-series data, (2) did not require a stomach empty of food, and (3) did not require killing of the animal. Conscious, non-fasted, HSD rats were gavaged with $5 \mu \mathrm{Ci}$ of $\left[3-{ }^{3} \mathrm{H}\right]$ glucose in $1 \mathrm{ml}$ of water. Rats were gently restrained by the tail, the tip of which was anaesthetized using $2 \%$ lidocaine. Tritium in plasma separated from tail blood collected $0,15,30,60,90$ and 120 min after gavage was detected in a beta-counter. Rats were injected subcutaneously with $0.1 \mathrm{ml}$ saline containing $0,0.1,0.3,1,10$ or $100 \mu \mathrm{g}$ of rat amylin 1 min before gavage ( $n=8,7,7,5,5,5$ respectively). 
Table 1. Gastric contents remaining $20 \mathrm{~min}$ after gavage

\begin{tabular}{llll}
\hline & Non-diabetic HSD & Non-diabetic BB & Diabetic BB \\
\hline Fasted $20 \mathrm{~h}(n)$ & $54.9 \pm 3.0 \%(20)$ & $27.0 \pm 3.8 \%(7)$ & not done \\
Fasted $6 \mathrm{~h}(n)$ & $50.9 \pm 4.7 \%(8)^{\mathrm{a}}$ & $38.9 \pm 9.2 \%(6)^{\mathrm{a}}$ & $9.7 \pm 1.7 \%(10)^{\mathrm{b}, \mathrm{c}}$ \\
\hline
\end{tabular}

Gastric contents are expressed as a fraction of those that could be recovered immediately after gavage in 2-3 separate rats run in the same assay. ${ }^{a}$ Not different from rats fasted $20 \mathrm{~h}^{\text {; }}{ }^{\mathrm{b}}$ differ- ent from HSD rats fasted $6 \mathrm{~h}(p<0.001)$; " different from nondiabetic $\mathrm{BB}$ rats fasted $6 \mathrm{~h}(p<0.001)$
Immunoassay for rat amylin. In a separate experiment to assess the change in plasma amylin concentrations that an effective dose of subcutaneous amylin produced, blood was sampled from the tails of six halothane-anaesthetized rats following s.c. bolus injection of either $1 \mu \mathrm{g}(n=3)$ or $10 \mu \mathrm{g}(n=3)$ of rat amylin. In another experiment, plasma amylin concentrations were compared in non-fasted HSD rats $(n=8)$ and in non-fasted diabetic $\mathrm{BB}$ rats $(n=5)$. The plasma from $250 \mu \mathrm{l}$ samples collected at 10 -min intervals was separated and frozen at $-20^{\circ} \mathrm{C}$ for analysis by a two-site immuno-enzymometric assay developed in-house.

To perform the immunoassay, black microtitre plates (Dynatech, Chantilly, Va., USA) were coated with the antibody F024-4.4 [Phelps JL, Blase E, Koda JE, unpublished data] by overnight incubation at $4{ }^{\circ} \mathrm{C}$ with $20 \mu \mathrm{g}$ antibody per $\mathrm{ml}$ in $50 \mathrm{mmol} / \mathrm{l}$ carbonate at $\mathrm{pH} 9.6$. Plates were washed with $0.05 \mathrm{~mol} / 1$ Tris $/ 0.15 \mathrm{~mol} / 1$ sodium chloride $/ 0.02 \%$ sodium azide $/ 0.1 \%$ Tween 20 (TBS/Tween), and blocked with $1.0 \%$ non-fat dry milk powder in the same carbonate buffer for $1 \mathrm{~h}$ at room temperature. Samples were thawed on ice, and diluted in $4 \%$ bovine serum albumin $200 \mathrm{mg} / \mathrm{dl}$ bovine cholesterol supertrate (Miles Pentex reagents, Miles Laboratories, Kankakee, Ill., USA) if necessary. Samples or standards were added to the coated and blocked plates and incubated for $1 \mathrm{~h}$ at room temperature. After washing, the F025-27 detection antibody conjugated to alkaline phosphatase was added. Antibody-enzyme coupling was performed using the maleimide alkaline phosphatase conjugation kit from Pierce Immunochemical Co (Rockford, Ill., USA). The conjugate was incubated for $3 \mathrm{~h}$ at room temperature, after which plates were washed thoroughly with Tris buffered saline. Bound enzyme was detected by incubation of the plates with the fluorescent substrate 4methylumbelliferyl phosphate at $50 \mu \mathrm{g} / \mathrm{ml}$ in $1 \mathrm{~mol} / \mathrm{l} \mathrm{di-}$ ethanolamine $/ 0.5 \mathrm{mmol} / \mathrm{MgCl}$, pH 9.8 for $40 \mathrm{~min}$ at room temperature. The fluorescent signal was measured with a Dynatech Microfluor plate reader, and data analysed on Multicalc software (Wallac, Gaithersburg, Md., USA). Concentrations of amylin in plasma samples were determined by comparison with a standard curve run in the same assay. When performed in this manner, the assay has a minimum detectable concentration of $2 \mathrm{pmol} / 1$.

\section{Statistical analysis}

Dose response curves for gastric emptying were fitted to a 4parameter logistic model using a least-squares iterative routine (ALLFIT, v2.7, NIH, MD) to derive the $\mathrm{ED}_{50}$. Since $\mathrm{ED}_{50}$ is log-normally distributed, it is expressed \pm standard error of the logarithm. Pairwise comparisons were performed using one-way analysis of variance and the Student-Newman-Keuls multiple comparisons test (Instat v2.0, GraphPad Software, San Diego, Calif., USA) using $p<0.05$ as the level of significance.

\section{Results}

Characteristics of diabetic rats. In eight non-fasted HSD rats, circulating amylin concentrations were $11.7 \pm 1.4 \mathrm{pmol} / \mathrm{l}$ (95\% CI 8.4-14.9 pmol/1). By comparison, amylin concentrations in five non-fasted spontaneously-diabetic BB rats were undetectable, affirming previous reports that such animals have a deficiency of amylin $[18,19]$.

Gastric emptying, qualitative observations. $\mathrm{BB}$ rats were killed and the gastric contents examined after a 6-h fast on 35 occasions; on no occasion was chyme apparent (0/35). In contrast, the stomach contents of non-diabetic HSD rats were examined after a 6-h fast on 44 occasions, and chyme observed on 19. Chisquare analysis of this pattern indicates a highly significant odds ratio $(p<0.0001$; Fisher's Exact Test; Instat v2.0, GraphPad Software, San Diego, Calif., USA). After a 20-h fast, the stomachs of non-diabetic rats were clear, an advantage when using the phenol-red absorbance method since possible absorbance artefacts due to turbidity were avoided.

Gastric emptying, quantitative observations. The fractions of dye remaining $20 \mathrm{~min}$ after gavage with phenol red, together with relevant statistical comparisons, are shown in Table 1 . In both HSD rats and in non-diabetic BB rats, emptying of dye after $20 \mathrm{~min}$ was the same whether animals were fasted for $6 \mathrm{~h}$ or for $20 \mathrm{~h}$. That is, period of fasting (within the 6-20 h range) did not appear to significantly affect gastric emptying measured by this technique.

The most notable result was gastric emptying in diabetic BB rats, which was significantly faster $(p<0.01-0.001)$ than in any of the four other treatment groups (i.e. non-diabetic animals). The observation that diabetic $\mathrm{BB}$ rats have a higher rate of gastric emptying than non-diabetic BB rats, a result supported by Nowak et al. [7], suggests that the observation is related to the presence of diabetes and is not merely associated with the BB strain.

Effects of amylin on gastric emptying - phenol red method. Because of the methodological constraints identified above, the effects of amylin were explored in non-diabetic HSD rats fasted $20 \mathrm{~h}$, and in diabetic $\mathrm{BB}$ rats fasted $6 \mathrm{~h}$ (Fig. 1). 


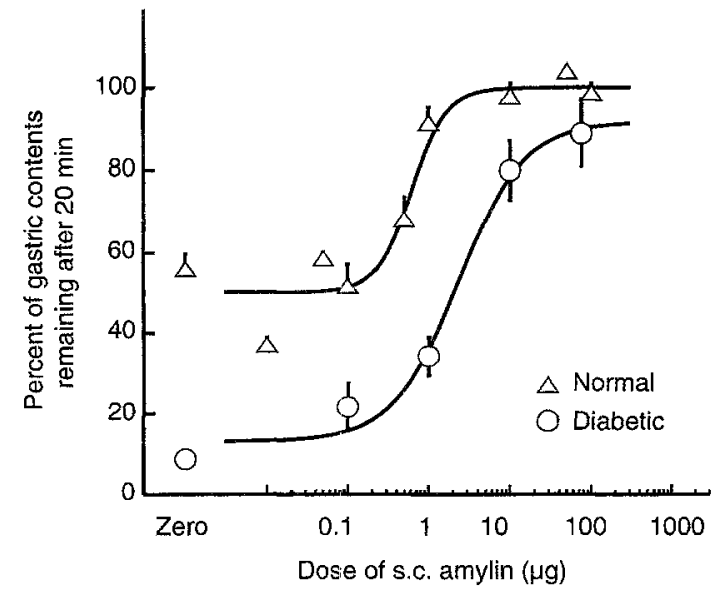

Fig. 1. Dose-response for the effects of prior s.c. injection of rat amylin on the retention of gastric contents 20 min after gavage in normal and diabetic BB rats. $n=3-9$ for each point. Symbols are means \pm SEM and the curves define the best fitting logistic functions. "Zero" indicates the fraction of gastric contents retained in normal and diabetic rats not treated with amylin (different at $p<0.001$ )

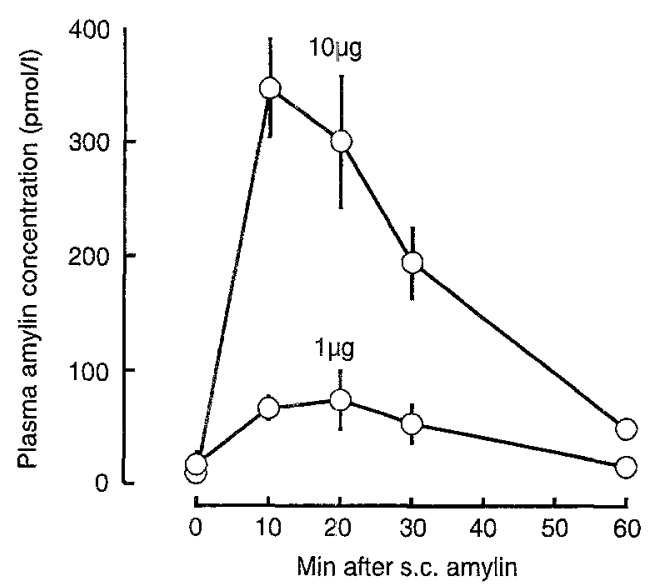

Fig. 2. Plasma amylin concentration measured after the subcutaneous injection of either $1 \mu \mathrm{g}$ or $10 \mu \mathrm{g}$ of synthetic rat amylin ( $n=3$ /group). Symbols are means \pm SEM

When subcutaneous amylin injections were given 5 min before gavage with phenol red indicator, there was a dose-dependent suppression of gastric emptying. Suppression of gastric emptying was complete in normal HSD rats administered $1 \mu \mathrm{g}$ of amylin, and in diabetic rats administered $10 \mu \mathrm{g}$ (gastric content was the same as immediately after gavage; $p=0.22$, $0.14)$. The $\mathrm{ED}_{50}$ for inhibition of gastric emptying in normal rats was $0.43 \mu \mathrm{g}(0.60 \mathrm{nmol}$ amylin $/ \mathrm{kg}$ body weight $) \pm 0.19 \log$ units, and was $2.2 \mu \mathrm{g}(2.3 \mathrm{nmol} /$ $\mathrm{kg}) \pm 0.18 \log$ units in diabetic rats.

Plasma amylin concentrations after subcutaneous injections. As shown in Figure 2, when three rats were injected subcutaneously with $1 \mu \mathrm{g}$ of rat amylin, the plasma concentration measured $10 \mathrm{~min}$ later was $66 \pm 10 \mathrm{pmol} / 1$ and the peak concentration, at
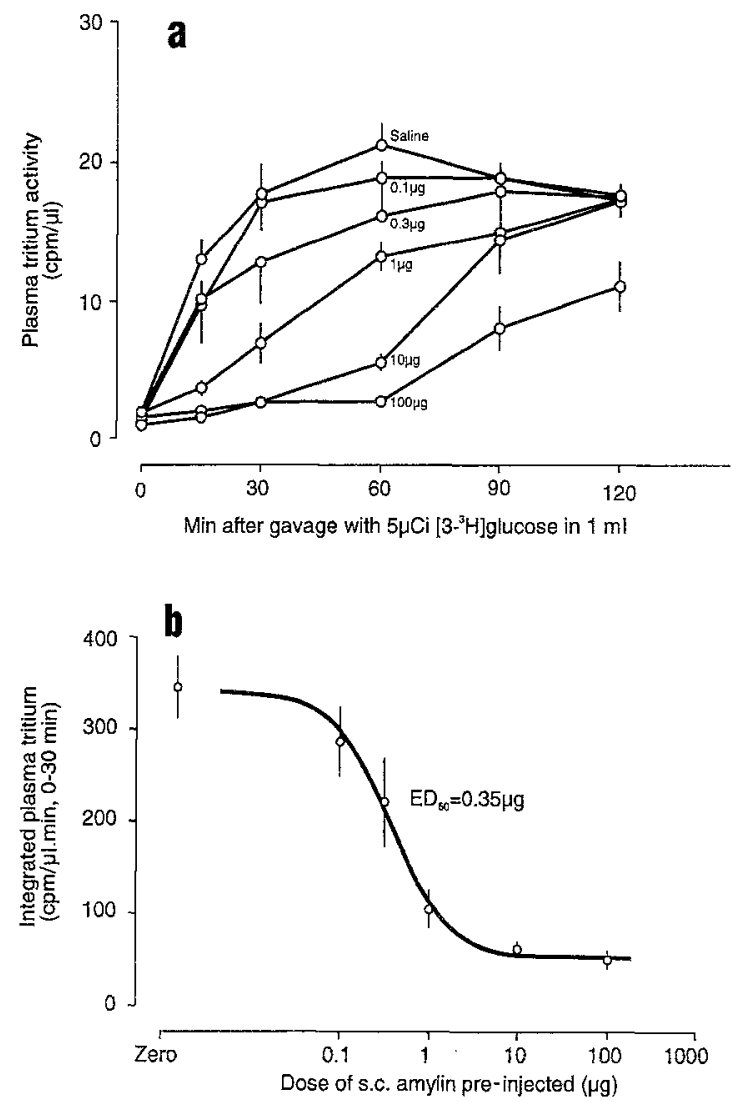

Fig.3. (a) Effect of pre-injection of rat amylin upon the increase in plasma tritium after gavage with [3- $\left.{ }^{3} \mathrm{H}\right]$ glucose in $1 \mathrm{ml}$ of water. Saline or the doses of amylin indicated was administered s.c. $5 \mathrm{~min}$ before gavage. Symbols are means \pm SEM. (b) Dose-response obtained by integrating the areas under the curves in (a) from 0 to $30 \mathrm{~min}$ after gavage. Symbols are means \pm SEM

$20 \mathrm{~min}$, was $74 \pm 26 \mathrm{pmol} / 1$. In three rats injected with a $10-\mu \mathrm{g}$ s.c. bolus, the corresponding, 10 - and 20 -min concentrations were $347 \pm 43 \mathrm{pmol} / \mathrm{l}$ and $301 \pm 57 \mathrm{pmol} / \mathrm{l}$, respectively.

Effects of amylin upon absorption of $\left[3{ }^{3} H\right]$ glucose. After gavage of saline pre-injected rats with tritiated glucose, plasma tritium increased rapidly $\left(\mathrm{t}^{1} / 2 \sim\right.$ $8 \mathrm{~min}$ ) to an assymptote that slowly declined, as shown in Figure 3 a. Subcutaneous pre-injection with amylin dose-dependently slowed and/or delayed the absorption of the label. Plasma tritium activity was integrated over $30 \mathrm{~min}$ to obtain the areas under the curve plotted as a function of amylin dose in Figure $3 \mathrm{~b}$. The $\mathrm{ED}_{50}$ derived from the logistic fit was $0.35 \mu \mathrm{g}$ of amylin. At amylin doses of 10 and $100 \mu \mathrm{g}$, the plasma tritium had increased very little by 15 min after gavage, indicating that the effect of amylin at this dose to suppress absorption of label must have been near complete by the time gavage was performed (1 min after s. c. amylin injection). 


\section{Discussion}

The data presented here reveal an accelerated rate of gastric emptying in an animal model of spontaneous autoimmune diabetes (IDDM). The present study also demonstrates that amylin has a potent effect on inhibiting gastric emptying in both normal and spontaneously diabetic rats. Thus, deficiency of amylin (a feature of these diabetic animals) is associated with accelerated gastric emptying, and exogenous amylin dose-dependently inhibits gastric emptying. The difference in gastric emptying of the acaloric gel between the diabetic and non-diabetic rats could reflect, at least in part, a tonic inhibition of gastric emptying by endogenous amylin, present in the non-diabetic animals but absent from the diabetic rats. It remains to be demonstrated whether the increment in plasma amylin after ingestion of a caloric load in non-diabetic rats would further slow gastric emptying.

The effects of amylin on gastric emptying reported here were assessed in a well-established rat model using an acaloric gel. In addition, we explored the use of a novel technique for measuring gavaged radiolabelled glucose, and obtained quantitatively similar amylin dose-response data. Advantages of the [3${ }^{3} \mathrm{H}$ ]glucose gavage technique include (1) technical simplicity, (2) availability of time course data, (3) ability to use animals in any metabolic state, including the fed state used in the present study, and (4) the ability to reuse animals, permitting replicated measures. $\left[3-{ }^{3} \mathrm{H}\right]$ glucose was chosen because the ultimate fate of the label is water; it therefore makes little difference whether the absorbed glucose remains as glucose or is metabolized to water, since either is represented by plasma tritium activity. A potential disadvantage of the technique is the slowly declining assymptote which plasma tritium approaches, perhaps due to sequestration of the label in glycogen, or to the relative dilution of the label as it becomes distributed from within the glucose space to within the water space, or less likely in the current time frame, to water clearance at the kidney. Such disappearance of tritium was of little practical consequence, however, since it was slow in comparison to the tritium appearance, modulated by amylin-sensitive processes. Another potential disadvantage of the [3${ }^{3} \mathrm{H}$ ]glucose gavage technique is that it does not distinguish between changes in absorption due to modulation of gastic emptying, and changes due to modulation of gut to blood transit. However, we have shown in rats with in situ perfused gut segments undergoing euglycaemic clamps, that systemically-delivered amylin does not affect the transit of glucose from gut to blood [Gedulin et al., unpublished data], and are therefore confident that the amylin-mediated changes in labelled glucose absorption observed in the present study reflect changes in gastric emptying rather than altered transit from gut to blood.
The findings from both phenol red and [3$\left.{ }^{3} \mathrm{H}\right]$ glucose gavage studies are consistent with those reported in conscious dogs [15] where continuous scintigraphy of the stomach followed ingestion of a ${ }^{99} \mathrm{Tc}$-labelled oral glucose load. In that model, concomitant intravenous amylin infusions potently inhibited gastric emptying, and delayed and reduced the rise in plasma glucose, consistent with gastric emptying being a rate-limiting step in the appearance of ingested glucose in plasma. While the effects of amylin on gastric emptying have not been reported in humans, it has been reported [20] that intravenous infusions of the human amylin analogue, tripro-amylin, reduce the rise in plasma glucose in IDDM volunteers after a meal, consistent with amylin regulating gastric emptying in humans.

From these findings, we can ask two important questions: (1) could amylin play a role in the physiological regulation of gastric emptying, and (2) what might be the consequences of disturbances of control of gastric emptying in IDDM?

Could amylin be a physiologic regulator of gastric emptying? The dose-response relationships shown in Figures 1 and 3, and the concentration-response relationship that can be additionally inferred from the dose-concentration data in Figure 2 indicate that gastric emptying is likely to be inhibited by concentrations of amylin reported to circulate in normal rats (16 pmol/l in young rats, $43 \mathrm{pmol} / \mathrm{l}$ in old rats [21]). Doses that $50 \%$ suppressed gastric emptying in normal rats were predicted to increase mean plasma amylin concentration by approximately $20 \mathrm{pmol} / 1$ (Fig. 1 data predict $19.6 \mathrm{pmol} / \mathrm{l}$; Fig. 3 data predict $22.1 \mathrm{pmol} / \mathrm{l}$ ). Similarly, $30-\mu \mathrm{g}$ doses of tripro-amylin that can effectively modulate postprandial glucose in man, also increase plasma concentrations by only about $20 \mathrm{pmol} / \mathrm{l}$ [22]. These data fit with the idea that amylin contributes to physiological control of gastric emptying, a concept also supported by the observation that gastric emptying was accelerated in $\mathrm{BB}$ diabetic rats, shown here and previously $[18,19]$ to be amylin deficient.

There are several recognized hormone-mediated systems that regulate the rate of gastric emptying [23]. For example, secretin is involved in a mechanism that ensures that acid is not released at a rate greater than that at which it can be neutralized. Cholecystokinin is involved in a feedback mechanism regulating the release of fat from the stomach [24]. Similar control may be exerted via gastrin and/or pancreatic polypeptide [25] upon the release of peptides.

There appears also to be a physiologic mechanism in non-diabetic humans that controls the release of carbohydrate from the stomach into the intestine to a rate of between 1.6 [26] and 2.1 [27] kcal/min ( 400-530 $\mathrm{mg}$ of glucose/min, approximately the rate of peripheral glucose disposal attainable with physiological insulin concentrations). This rate of 
release was reported to be maintained over a range of ingested glucose concentrations and glucose loads [27]. The intermediaries responsible for such regulation are unclear, although gastric inhibitory polypeptide (GIP) has been proposed to play some part [28].

Since amylin is secreted from beta-cells in response to glucose and incretins such as glucagon-like peptide-1 (GLP-1) [12] and gastric inhibitory peptide (GIP), it is well-placed to participate in a feedback loop controlling the transit of chyme from stomach to intestine, and thus, the subsequent absorption of glucose.

It should be pointed out that the present studies indicate that amylin can potently regulate gastric emptying, but address neither a specific site of action, nor a molecular mechanism. Amylin may act, for example, on central or enteric nervous systems, or via known hormones such as GIP, cholecystokinin or motilin, or directly on gastrointestinal smooth muscle. Whatever the mechanism, it is apparent from time course data obtained using the $\left[3{ }^{3} \mathrm{H}\right]$ glucose gavage technique, that amylin action on the stomach is rapid; it can be maximal within 1 min of a subcutaneous amylin injection.

What are the consequences of accelerated gastric emptying in IDDM? A meal or an oral glucose load can contain many times the 10-20 g of free glucose typically present in the adult human. Thus increasing the transit of glucose from gut to plasma may have major impact upon glucose control by (1) exaggerating the postprandial rise in glucose and (2) prematurely depleting the reserve of unabsorbed glucose sequestered in the gut. The data of Pehling et al. [5] appear to show such a pattern. Those authors observed the appearance of ingested isotopic glucose in IDDM patients whose endogenous glucose production, fasting glucose concentration and rate of glucose utilization had been normalized by continuous subcutaneous insulin infusion. Compared to non-diabetic control subjects, the diabetic subjects had a $60 \%$ increase in the initial appearance of meal-derived glucose. This was accompanied by a similar increase in total glucose appearance and a doubling of the postprandial glucose increment, followed by a decline in these variables that preceeded the decline observed in non-diabetic subjects.

In conclusion, we have shown that gastric emptying is accelerated in an animal model of IDDM, a condition of amylin deficiency [13]. Exogenous amylin potently and dose-dependently inhibits gastric emptying. Since gastric emptying appears to be an important component of glucose homeostasis, these findings support the proposal that amylin deficiency could disrupt the normal control of gastric emptying and thereby contribute to the postprandial hyperglycaemia characteristic of IDDM. Studies in man are underway to further examine this proposition.
Acknowledgements. We gratefully acknowledge the technical contributions of Ms. S. Provost, Ms. H. Clarke, Ms. P.Carlo, Ms. P.Smith, Ms. L. Jodka, Ms. D. Greene and Ms. E.Larson and the secretarial assistance of Ms. N.Gallaher-Wakefield.

\section{References}

1. Horowitz M, Fraser R (1994) Disordered gastric motor function in diabetes mellitus. Diabetologia 37: 543-551

2. Cavallo-Perin P, Aimo G, Mazzillo A, Riccardini F, Pagano G (1991) Gastric emptying of liquids and solids evaluated by acetaminophen test in diabetic patients with and without autonomic neuropathy. Riv Eur Sci Med Farmacol 13: 205-209

3. Nakanome C, Akai H, Hongo M et al. (1983) Disturbances of the alimentary tract motility and hypermotilinemia in the patients with diabetes mellitus. Tohoku J Exp Med 139: 205-215

4. Phillips WT, Schwartz JG, McMahan CA (1992) Rapid gastric emptying of an oral glucose solution in type 2 diabetic patients. J Nucl Med 33: 1496-1500

5. Pehling G, Tessari P, Gerich JE, Haymond MW, Service FJ, Rizza RA (1984) Abnormal meal carbohydrate disposition in insulin-dependent diabetes. Relative contributions of endogenous glucose production and initial splanchnic uptake and effect of intensive insulin therapy. $J$ Clin Invest 74: 985-991

6. Plourde V, St-Pierre S, Fournier A, Tache Y (1993) CGRP [8-37] blocks the inhibition of gastric emptying induced by intravenous injection of $\alpha$ CGRP in rats. Life Sci 52: 857862

7. Nowak TV, Roza AM, Weisbruch JP, Brosnan MR (1994) Accelerated gastric emptying in diabetic rodents - effect of insulin treatment and pancreas transplantation. J Lab Clin Med 123: 110-116

8. de Boer SY, Masclee AA, Lamers CB (1992) Effect of hyperglycemia on gastrointestinal and gallbladder motility. Scand J Gastroenterol Suppl 194: 13-18

9. Fraser R, Horowitz M, Dent J (1991) Hyperglycaemia stimulates pyloric motility in normal subjects. Gut 32: $475-$ 478

10. Argiles JM, Zegri A, Arbos J, Garcia C, Lopez-Soriano FJ (1992) The role of insulin in the intestinal absorption of glucose in the rat. Int J Biochem 24: 631-636

11. Ogawa A, Harris V, McCorkle SK, Unger RH, Luskey KL (1990) Amylin secretion from the rat pancreas and its selective loss after streptozotocin treatment. J Clin Invest 85: 973-976

12. Inoue K, Hisatomi A, Umeda F, Nawata H (1991) Effects of glucagon-like peptide 1 (7-36) amide and glucagon release on amylin release from perfused rat pancreas. Horm Metab Res 23: 407-409

13. Koda JE, Fineman M, Rink TJ, Dailey GE, Muchmore DB, Linarelli LG (1992) Amylin concentrations and glucose control. Lancet 339: 1179-1180

14. Kolterman O, Gottlieb A, Moyses C (1994) Amylin agonist, $\mathrm{AC}-137$, reduces postprandial hyperglycemia in subjects with insulin dependent diabetes mellitus (IDDM). Diabetes 43: 78A (Abstract)

15. Brown K, Menius A, Sandefer E, Edwards J, James M (1994) The effects of amylin on changes in plasma glucose and gastric emptying following an oral glucose load in conscious dogs. Diabetes 43: 172A (Abstract)

16. Gedulin B, Vine W, Rink T (1994) Accelerated gastric emptying in insulin-treated BB/W (IDDM) rats. Diabetes 43: 134A (Abstract) 
17. Scarpignato C, Capovilla T, Bertaccini G (1980) Action of caerulein on gastric emptying of the conscious rat. Arch Int Pharmacodyn Ther 246: 286-294

18. Huang HS, Cooper GJS, Young AA, Johnson MJ (1991) Deficiency of amylin expression in the pancreas of autoimmune BB/Wor diabetic rats. J Cell Biochem 15 Part B: 67

19. Bretherton-Watt D, Ghatei MA, Legon S, Jamal H, Suda K, Bloom SR (1991) Depletion of islet amyloid polypeptide in the spontaneously diabetic (BB) Wistar rat. J Mol Endocrinol 6: 3-7

20. Kolterman O, Kisicki JC, Peltier L, Gottlieb A, Moyses C (1994) Infusion of amylin agonist AC-0137 reduces postprandial hyperglycemia in subjects with type 1 diabetes. Clin Res 42: 87A (Abstract)

21. Pieber TR, Roitelman J, Lee Y, Luskey KL, Stein DT (1994) Direct plasma radioimmunoassay for rat amylin-(137): concentrations with acquired and genetic obesity. Am J Physiol 267: E156-E164

22. Kolterman OG, Gottlieb AB, Moyses CJ (1994) Administration of tripro-amylin reduces postprandial hyperglycemia in subjects with juvenile-onset diabetes. Diabetologia 37: A72 (Abstract)

23. Kutchai HC (1988) Gastrointestinal motility. In: Berne RM, Levy MN (eds) Physiology. CV Mosby, St Louis, pp. 669-670

24. Liddle RA, Rushakoff RJ, Morita ET, Beccaria L, Carter JD, Goldfine ID (1988) Physiological role for cholecystokinin in reducing postprandial hyperglycemia in humans. J Clin Invest 81: 1675-1681

25. Okumura T, Pappas TN, Taylor IL (1994) Intracisternal injection of pancreatic polypeptide stimulates gastric emptying in rats. Neurosci Lett 178: 167-170

26. Horowitz M, Edelbroek MA, Wishart JM, Straathof JW (1993) Relationship between oral glucose tolerance and gastric emptying in normal healthy subjects. Diabetologia 36: $857-862$

27. Brener W, Hendrix TR, McHugh PR (1983) Regulation of the gastric emptying of glucose. Gastroenterology 85: 76-82

28. Thor P, Laskiewicz J, Konturek SJ, Creutzfeldt W (1987) Role of GIP and insulin in glucose-induced changes in intestinal motility patterns. Am J Physiol 252: G8-G12 